\title{
"Es porque no le ponen onda!": prácticas de comensalidad en la escuela
}

"It's because They don't Want To Do It": Children and Commensality Practices at School

Artículo de investigación | Research article

Fecha de recepción: 05 de julio de 2019 Fecha de aceptación: 22 de agosto de 2019 Fecha de disponibilidad en línea: mayo de 2021

doi: 10.11144/Javeriana.m14.epnp

Silvina del Carmen Fernández

fernandez.silvina.17@gmail.com Instituto de Formación Docente Continua Barlloche, Río Negro, Argentina (D) ORCID: https://orcid.org/0000-0002-9851-4821

Para citar este artículo | To cite this article Fernández, S. del C. (2021). "iEs porque no le ponen onda!": prácticas de comensalidad en la escuela. magis, Revista Internacional de Investigación en Educación, 14, 1-25. doi: 10.11144/Javeriana.m14.epnp 


\title{
Resumen
}

Partiendo de una etnografía realizada en una escuela primaria estatal de la provincia de Buenos Aires, Argentina, abordaré la perspectiva de Ixs niñxs sobre la comida y las prácticas de comensalidad en torno al comedor. Lxs niñxs aportaron ideas centrales para comprender los modos de comer en la escuela, tensionando elementos del sentido común y los modos habituales de estudiar la temática. Asimismo, sus perspectivas permitieron exponer lógicas organizativas de la alimentación escolar que no necesariamente priorizan una alimentación "adecuada". De este modo analizaré la agencia y las formas de participación política de lxs niñxs en relación con la alimentación.

\section{Palabras clave}

Alimentación escolar; estudiante de primaria; política; etnografía

\begin{abstract}
Starting from an ethnography carried out in a state primary school in the province of Buenos Aires, Argentina, I will approach the children's perspective about food and eating practices in the school restaurant. Children contributed with main ideas to understand the table manners at school, stressing elements of common sense and usual ways to approach these aspects. Likewise, their perspectives allowed to expose meal-time institutional logics of schools that do not necessarily focus on "adequate" eating practices. Thereby, I will analyze the capacity and roles in defining them and ways of political participation of children in relation to eating.
\end{abstract}

\section{Keywords}

School meals; primary school students; politics; ethnography 


\section{Descripción del artículo | Article description}

Este artículo de investigación es parte del trabajo de mi tesis doctoral en curso, La alimentación escolar, el comedor y lxs auxiliares en las disputas en torno a la autoridad en la escuela. En este realizo una etnografía sobre procesos políticos escolares, sobre la alimentación y el comedor escolar de una escuela primaria estatal de la localidad Gregorio de Laferrere, del municipio de La Matanza, Buenos Aires, Argentina.

\section{Introducción}

En este trabajo busco exponer algunos análisis sobre la perspectiva de Ixs niñxs ${ }^{1}$ en torno a la alimentación y las prácticas de comensalidad que se desarrollan en el comedor de una escuela pública estatal de Gregorio de Laferrere, de La Matanza, provincia de Buenos Aires, Argentina. La alimentación en el contexto escolar como tema de estudio habitualmente ha sido abordada atendiendo a los fenómenos nutricionales que en sus marcos se producen (Bonzi \& Bravo-Luna, 2008; Padilla, 2011; Torres, 2013; Tovo, 2013). Sin embargo, desde un enfoque etnográfico, la descripción y el análisis de las dinámicas cotidianas puestas en juego en el funcionamiento de los comedores escolares, uno de los espacios prioritarios para analizar la alimentación en la escuela, permiten visualizar las interacciones entre Ixs distintxs actores involucradxs y cómo estas producen fenómenos educativos complejos.

La alimentación escolar en Argentina ha acompañado a la escuela prácticamente desde sus orígenes. El surgimiento del sistema educativo nacional, a principios del siglo XX, estuvo mediado por marcos ideológicos higienistas, que promovían la importancia de la nutrición de Ixs niñxs, dado su carácter de condicionante para los aprendizajes. Desde entonces, las políticas públicas estatales promotoras de la alimentación escolar en sus diversos formatos (copa de leche, miga de pan o comedor escolar) han fluctuado. Los puntos de mayor incidencia remiten a períodos de crisis económica y social, en los cuales los espacios de comensalía públicos (comedores barriales, escolares y merenderos) aumentan. La alimentación en el contexto escolar ha llegado hasta nuestros días, siendo considerada

1 En este trabajo se hará uso de la letra $x$ para referirse a grupos de personas cuya adscripcion de género o identificación con un pronombre en particular no se conozca. Considero que la utilización de la $x$ es una posibilidad de producción de lenguaje no binario. De este modo, con su uso me distancio de aquel lenguaje que remite al mal llamado "genérico" masculino, como del uso del -os/-as, que también colabora con la definición de binarismos. 
como un derecho, sobre todo para aquellxs niñxs que "la necesitan". Existe a lo largo y ancho del país una diversidad de formatos para implementar la alimentación escolar. Mientras en algunos lugares solo se garantiza el refrigerio (desayuno o merienda), en otros se brinda, también, almuerzo. Los modos en los que se ofrece la comida en la escuela son también diversos²: algunas provincias o municipios han tercerizado el servicio y a las escuelas llegan viandas ya preparadas por empresas privadas; en otras, las escuelas cuentan con cocina y personal a cargo, por lo que los alimentos se preparan allí mismo.

La historia de la alimentación escolar y en particular de los comedores no se ha producido sin tensiones ni contradicciones. Ciertos debates en el campo educativo sobre el papel del docente y las responsabilidades específicas de las escuelas produjeron discusiones en torno a la alimentación como parte de las tareas asistenciales que quitaban espacio al trabajo de enseñar. Si bien no se producía en estos términos, desde los inicios de mi trabajo de campo el comedor escolar fue señalado por docentes y directivos como un espacio escolar atravesado por aspectos problemáticos. Posteriormente, el cocinero y Ixs auxiliares de servicio que trabajaban en el comedor escolar también destacaron algunas tensiones que involucraban a diferentes actores. Lxs docentes con quienes conversaba desprestigiaban el funcionamiento del comedor refiriendo la mala calidad de la comida, la falta de idoneidad en la tarea de sus responsables y la dinámica poco amable en la que se le da de comer a Ixs chicxs. Por su parte, el cocinero y Ixs auxiliares denunciaban la ausencia de Ixs maestrxs y la falta de autoridad de Ixs directivxs para exigir la presencia de Ixs primerxs en este espacio. Dado que eran muchxs niñxs y que algunxs de ellxs se "portaban mal", ingresaban a deshoras o con sus hermanxs pequeñxs (no alumnxs de la escuela), el cocinero y Ixs auxiliares reclamaban constantemente la necesaria presencia de Ixs maestrxs. En tanto, Ixs directivxs reconocían falencias en el funcionamiento del comedor, sin embargo, advertían que el accionar "corporativo" del cocinero y Ixs auxiliares imposibilitaban mejoras en el servicio. Rápidamente consideré estas tensiones en mi estudio, y fueron comprendidas como parte de las disputas de poder que tienen lugar en las escuelas, y que permiten analizar fenómenos que dan forma a la vida política escolar. Sin embargo, fue recién cuando mi trabajo de investigación estaba avanzado que pude comprender a Ixs niñxs como actores que participaban y, por ende, también producían esas tensiones aquí analizadas como parte de las relaciones políticas escolares.

2 Me refiero aquí a escuelas públicas estatales. En las escuelas privadas y de gestión privada Ixs estudiantes deben pagar para acceder al servicio, y la oferta de alimentos suele estar a cargo de servicios de bufetes particulares. 
Lxs niñxs fueron durante todo mi trabajo de campo consideradxs como interlocutores significativxs para comprender los modos de funcionamiento del comedor: he conversado con ellxs en diferentes momentos y lugares, compartido almuerzos en el comedor, actividades en el aula y en talleres; también acompañaron la realización del trabajo de campo tomando fotografías y realizando encuestas y entrevistas, actividades que incluso propusieron y realizaron por iniciativa propia. Sin embargo, no lograba colocar sus visiones sobre el comedor y la alimentación en el mismo plano que las de Ixs otrxs miembros de la escuela. No me resultaba tan claro que sus participaciones también eran parte de los conflictos y las tensiones que producía el funcionamiento del comedor escolar ¿Acaso sus intervenciones eran "menos" políticas que las de otrxs actores? ¿Sus valoraciones, sus discursos y acciones con relación al tema producían menos tensión? Una situación vivida con dos niñas en el comedor fue el puntapié para reconsiderar muchas otras interacciones en las que Ixs niñxs se referían al comedor o la alimentación en la escuela. Al volver sobre los documentos de campo advertí diferentes momentos que, si bien habían llamado mi atención, no habían ingresado en la reconstrucción de las disputas que producía el comedor. Además de percibir claramente que el contenido de lo que Ixs niñxs manifestaban también era parte de las tensiones, pude advertir que el modo en el que lo hacían refería a aspectos centrales para estudiar la alimentación: el gusto y las prácticas de comensalidad.

Para dar cuenta de la perspectiva de Ixs niñxs, organizo este trabajo en cinco apartados: en el primero detallo el abordaje metodológico en el que está enmarcado el estudio; en el segundo recupero algunos recorridos conceptuales para pensar el vínculo entre escuela, política, infancias y alimentación; en el tercero reconstruyo una situación con dos niñas que produjo mi perplejidad y me permitió considerar seriamente las intervenciones de Ixs niñxs como parte de los conflictos en torno al comedor; en el cuarto describo una serie de intercambios producidos sobre la comida en la elaboración de una encuesta sobre alimentación en la escuela y en el diálogo a partir de sus resultados, para abordar las lógicas escolares que sostienen la organización de la alimentación en la escuela. Por último, reflexiono sobre la relevancia de considerar las perspectivas de Ixs niñxs y su potencialidad política para pensar y reconceptualizar la alimentación en contexto escolar, más allá de los aspectos nutricionales.

\section{Algunas notas sobre escuela, política, infancias y alimentación}

En este trabajo consideraré a la política tal como ha sido estudiada por el campo de la antropología, es decir, como una dimensión presente en 
toda relación social, que, más allá de la forma que tome y de los procesos que involucre, alude a prácticas en la esfera pública, siempre vinculadas a disputas por el poder y a objetivos colectivos (Swart, Turner \& Tuden, 1966). Este modo de comprensión, alejado de las "visiones jurídicas" (Foucault, 2003) que ligan la política a los ámbitos del Estado, posibilita entender mejor cómo se entretejen las relaciones de poder, sus ramificaciones y las prácticas a las que dan lugar (Abélès, 2004). Este enfoque no ha sido el más desplegado en los estudios sociales, y menos aún en las investigaciones en el campo de la educación en Argentina (Milstein, Fernández, García, García \& Paladino, 2006), lo que conlleva la dificultad para comprender a las instituciones educativas como espacios en los que se producen procesos políticos. Este aspecto se combina, o tal vez sea parte, de otra representación muy instalada acerca de la escuela, en la que se considera como un ámbito de separación y resguardo de Ixs niñxs y jóvenes de otros ámbitos potenciales de socialización (como la calle, la fábrica, los cultos, entre otros) y del entorno social percibido como problemático (Batallán \& Campanini, 2008). Tal separación de Ixs niñxs y jóvenes del mundo doméstico-privado se fundamentó asimismo en el mandato moderno por el cual la escuela sería la institución pública encargada de la instrucción y del aprendizaje del conocimiento universal y de la convivencia ciudadana responsable (Batallán \& Campanini, 2008). Sin embargo, es por ese mismo mandato y su razón de ser - la educación de las nuevas generacionesque el aspecto político es fundante y estructurante de la vida escolar en todos sus aspectos. De modo complementario, tal como plantea Batallán (2003), la dinámica de los vínculos intraescolares que responden a la lógica burocrática de un sistema jerárquico-vertical refuerza la mencionada concepción sobre el poder que enajena de su potencialidad política también a Ixs adultxs y produce una exclusión como categoría analítica pertinente para reflexionar sobre la escuela.

La imagen extendida de la institución escolar como espacio neutral y de sus actores como alejados del accionar político se vincula - a la vezcon la visión dominante acerca de Ixs niñxs, en la que se subestima sus posibilidades de comprensión y, por ende, la imposibilidad para accionar en temas considerados como "cosas de adultxs", en cuanto estxs no contarían con un pleno desarrollo y carecerían de elementos, conocimientos, hábitos y demás facultades que habilitarían a los seres humanos como adultxs socializadxs (Milstein \& Otaso, 2013). De este modo, se restringen y limitan los contextos de sus acciones y comportamientos, y se Ixs desvaloriza en cuanto a sus capacidades plenas de participación y agenciamiento en la vida social.

Por su parte, la alimentación será aquí considerada como parte de un proceso que hace al sujeto desde lo biológico, al aportarle las energías 
naturales necesarias para vivir, pero que también lo interpela desde lo social-subjetivo. En el acto de comer, el sujeto participa y se apropia de un sistema culinario particular del grupo social, que implica una visión del mundo, una trama de sentidos. Esos diferentes modos de comer y beber han sido estudiados desde el campo de las ciencias sociales a través de la noción de comensalidad, definida como una forma de actividad ritual pública centrada en el consumo comunal de comida y bebida para un propósito u ocasión especial (Bray, 2003; Clarke, 2001; Dietler, 1996; 2001; Wiessener, 2001). En este sentido, las comidas pueden ser analizadas como sitios culturales para la socialización de las personas, en cuanto miembros adecuados y competentes de una sociedad (Ochs \& Shohet, 2014). Los sitios culturales son conceptualizados como arenas localizadas tempoespacialmente, históricamente durables aunque transformables, socialmente organizadas y organizadoras, cargadas de significados simbólicos y mediadas por artefactos materiales. Adquieren vida a través de la participación social recurrente y alcanzan la permanencia a través de los esfuerzos por socializar a los novatos en las preferencias, los sentimientos y las acciones que afianzan una participación significativa. Con esta noción de sitio cultural, las comidas pueden ser tratadas como arenas fecundas para la producción de sociabilidad, moralidades y conocimientos locales del mundo. Más que un conjunto de comportamientos, costumbres, símbolos y reglas que los expertxs transmiten y lxs niñxs o novatxs aprenden, el conocimiento y las prácticas culturales asociadas con las comidas son recreados y alterados a través de relaciones sociales experiencialmente asimétricas. Un conjunto de investigadores ha analizado cómo, en ese marco, Ixs niñxs y su capacidad de agencia se apropian y recrean la cultura dentro de sus propios esquemas de pensamiento, sentimiento y actuación en el mundo (Cole \& Cole, 1996; LeVine, 1999; Mead, 1934).

En relación a la alimentación en contextos escolares, esta visión adoptada se encuentra menos extendida que la perspectiva que analiza los consumos de los sujetos y su calidad nutricional. Las investigaciones que derivan principalmente de las ciencias de la salud ponen el foco en las "malas" decisiones alimentarias que realizan Ixs niñxs, en el actual "ambiente obesogénico" con el que caracterizan la época actual. Desde estos enfoques, Ixs niñxs serían presa fácil de las ofertas de productos saturados en azúcares, grasas e hidratos de carbono, los cuales entrarían dentro de sus preferencias. Esto les otorga una suerte de posición pasiva, en la que Ixs niñxs son víctimas del actual sistema alimenticio, a la vez que Ixs responsabiliza por optar por productos "poco saludables". Tal como han mostrado variados estudios etnográficos, lejos de asumir un rol pasivo, la contribución de Ixs niñxs a la subsistencia doméstica, en general, y a la alimentaria, en 
particular, ocurre tempranamente, sobre todo en sociedades rurales e indígenas (Cervera-Montejano, 2009; Mignot, 1996; Remorini, 2015; Rogoff, Moore, Behnosh, Dexter, Correa-Chavez \& Solís, 2007; Rogoff, Paradise, Mejía-Arauz, Correa-Chávez \& Angelillo, 2003). También lo hacen en las zonas urbanas cuando son Ixs responsables de dirigirse a los almacenes a comprar lo que les indican sus padres, madres o familiares, cuando asisten a espacios de comensalía públicos en sus barrios o cuando simplemente eligen no ingerir ciertos alimentos. Como aquí evidencio, respecto a la alimentación en el contexto escolar, Ixs niñxs no solo asumen posiciones críticas con respecto a la comida que se les ofrece en el comedor, sino que también toman postura sobre los modos organizativos. En función de sus perspectivas toman decisiones que, en algunos casos, se traduce en no terminar el plato de comida o, directamente, en no asistir al comedor. De este modo, participan y producen las tensiones que tienen lugar en la escuela como parte de la implementación del comedor y que aquí, al ser comprendidas como políticas, permiten considerar a Ixs niñxs como actores con agencia y potencialidad de intervenir en los llamados "temas de adultxs".

\section{Enfoque metodológico}

Este artículo es producto del trabajo de investigación etnográfico realizado en el marco de mi tesis doctoral, aún en curso, cuyo trabajo de campo fue centralmente realizado entre marzo de 2015 y diciembre de 2017. El "estar ahí" recurrentemente, aspecto que caracteriza el trabajo de campo etnográfico, observando, participando y construyendo vínculos con lxs interlocutores, ha posibilitado explorar la alimentación en la escuela y el funcionamiento del comedor más allá de los aparentes problemas que suscitan o de los modos habituales de abordarlos desde el campo de la investigación. El complejo entramado de relaciones, valoraciones y prácticas desarrolladas alrededor del funcionamiento del comedor y sus implicancias en la alimentación en el contexto escolar han resultado posibles de ser descritos y analizados por ser la etnografía un enfoque que prioriza las perspectivas de Ixs actores, sus dichos y actos. Por ello, en mi trabajo de campo me interesó compartir diversos momentos con diferentes personas en la escuela, pero también afuera de ella, a través de mi participación de las reuniones de la Red Interinstitucional, de la cual era parte la institución, junto a otros centros educativos; con las médicas pediatras del hospital más cercano, y con algunas madres, referentes del barrio en el que vivían la mayoría de Ixs niñxs de la escuela. Como parte del trabajo de la Red realizamos talleres con niñxs y con sus familias, lo cual me permitió visitar varias escuelas de la zona, los barrios aledaños y el hospital. 
De manera particular en este estudio consideré la perspectiva de Ixs niñxs, alumnxs de la escuela, con quienes conversé en diferentes espacios y momentos, como recreos, almuerzos en el comedor, pasillos y clases. Además, con algunxs de ellxs compartimos talleres ${ }^{3}$ en los que reflexionamos sobre la alimentación, mediante la elaboración de cuestionarios para entrevistar al cocinero y lxs auxiliares; la elección de "personas importantes" para entrevistar; el compartir recetas de sus comidas preferidas; la toma de fotografías, y la elaboración de collages a partir de ellas. Particularmente, y como parte de un proyecto escolar, con uno de los grupos de sexto grado (niñxs entre 11 y 13 años) elaboramos una encuesta sobre alimentación escolar que, posteriormente, aplicamos al conjunto de Ixs estudiantes de la escuela, en ambos turnos (mañana y tarde). Los diálogos con Ixs niñxs en los diferentes momentos y actividades posibilitaron el extrañamiento de las explicaciones habituales que muchas personas solían dar sobre el tema de la alimentación en el contexto escolar, señalando, además, formas novedosas de pensarlo y definirlo.

A continuación, me detendré en una situación que compartí con dos niñas en la puerta del comedor, la cual produjo mi perplejidad por la intensidad en su contenido. A raíz de estas interacciones fue, justamente, que pude considerar seriamente las posiciones de Ixs niñxs, revisando muchos otros momentos y resituándolos como parte del entramado político en relación a la alimentación y el comedor.

\section{"Eso es porque no le ponen onda"4}

Un mediodía del mes de junio del año 2016, a más de un año de iniciado mi trabajo de campo, nos encontrábamos con Lina, una alumna de cuarto grado. Conversábamos en la puerta del comedor mientras esperábamos que terminaran de comer Ixs alumnxs de los primeros grados. Lina iba todos los días al comedor y yo solía ingresar con ella para observar y conversar con otrxs chicxs; nos conocíamos porque ella había participado en los talleres durante el año anterior. En ese momento se acercó otra niña, que saludó a Lina y le preguntó quién era yo. Me presenté e intenté explicarle mi trabajo como investigadora en la escuela, y le pedí a Lina que me ayudara a contarle el trabajo del que ella había participado. Agregué que

3 Estos talleres fueron realizados con niñxs de tercero, cuarto, quinto y sexto grado. Nos reuníamos en el espacio del Equipo de Orientación Escolar (EOE), durante el horario de clases. Dichos talleres fueron planificados con la psicóloga y la psicopedagoga del EOE.

4 Ponerle onda en Argentina es un modismo de uso habitual que, generalmente, significa 'hacer algo con mucho esmero y ganas'. 
me interesaba conocer sobre la alimentación en la escuela, ante lo que la niña, quien ya se había presentado como Antonia, me interrumpió, y dijo: "iAh! ¿Vos venís a controlar la comida acá? iAh, sos inspectora!". Sonriendo miré a Lina y le respondí a Antonia, entre risas: "iNo! Yo no inspecciono nada, vengo a conocer... Me interesa saber qué piensan ustedes, los chicos, pero no controlo". Como se interesó por el grabador de voz que sostenía con mi mano, le pregunté a Antonia si podía entrevistarla, y poniendo bien derecha la espalda, parándose erguida me respondió que sí.

Silvina: — ¿Venís seguido al comedor?

Antonia: —Vengo a veces... Cuando mi mamá no está en mi casa.

Silvina: — ¿Y qué pensás de la comida de la escuela?

Antonia (mira hacia arriba y después de unos segundos responde): - A veces la comida es rica y a veces no... iEso es porque no le ponen onda!

Silvina: —iAh, mirá! Y... ¿cómo es ponerle onda?

Antonia: —Mmmm, hacerla con ganas, iPonerle amor! iHacerla con amor!

Por su parte, Lina, quien asistía diariamente al comedor y mantenía un vínculo de mayor confianza con el cocinero, se acercaba al grabador para decir "Es rica la comida, siempre es rica", mientras miraba a Antonia seriamente. Algunos minutos después ingresamos al comedor, yo extasiada por la definición que Antonia había logrado sobre el trabajo de cocinar en la escuela y la comida. Mientras ambas niñas comían, Antonia se dirigió a mí y expresó: "Cuando venís vos, la inspectora, la comida es mejor". Sorprendida con la insistencia le repetí sonriendo que no era inspectora, pero ella volvió a decir: "Es mejor la comida".

La contundencia de las expresiones de Antonia me permitió advertir que las valoraciones de lxs niñxs podían ser ingresadas en ese entramado de tensiones que se producía alrededor del comedor. Desde mis inicios del trabajo de campo en esta escuela de la localidad de Gregorio de Laferrere, la alimentación escolar y, en particular, el comedor habían sido definidos por sus problemas. No solo Ixs miembrxs de la escuela lo señalaban, el propio Consejo Escolar y el municipio local, mediante el área de Salud Escolar, se encontraban fomentando la creación de proyectos escolares que "promovieran hábitos saludables", entre ellos, los alimenticios. Por eso, poco después de comenzar a visitar la escuela el entonces director y lxs profesionales del Equipo de Orientación Escolar — en adelante, EOE- me invitaron 
a participar de la elaboración de un proyecto sobre alimentación escolar. Fue en ese marco que realizamos una serie de talleres y actividades con Ixs niñxs, entre las que se destacaron la elaboración de una encuesta con Ixs alumnxs de sexto grado. En este trabajo, uno de los primeros hallazgos, a partir de las producciones de Ixs niñxs, fue la centralidad que ellxs le dieron al cocinero y a Ixs auxiliares de servicio. Este grupo de trabajadores, aunque no considerados por los estudios relativos a la vida escolar en general, ni por aquellos asociados directamente a su trabajo — como los abocados a estudiar la implementación y el funcionamiento de los comedores-, son actores relevantes para comprender buena parte de la cotidianidad y la socialización escolar de Ixs niñxs. Lxs auxiliares, y en particular quienes se desempeñan como cocinero y como auxiliar de cocina, se ocupan de administrar todos los aspectos materiales concretos del funcionamiento del comedor y el refrigerio escolar. El cocinero y el auxiliar de cocina son quienes deben recibir la mercadería de parte de Ixs proveedores de alimentos, almacenarla y preservarla en condiciones adecuadas para la elaboración de los menús, realizar tareas específicas de preparación de alimentos (aplicando las indicaciones dadas en las circulares correspondientes para la cumplimentación de los menús en lo referente a forma de utilización y dosificación de los ingredientes) y distribuir correctamente las porciones en el comedor. A la vez deben ocuparse de la limpieza de la vajilla, así como también del comedor y la cocina. Por reglamentación ${ }^{5}$, el cocinero y la auxiliar de cocina deben recibir diariamente y por escrito, de parte de la Dirección, el menú y la cantidad de porciones a preparar. Sin embargo, en esta escuela la definición de ambas cuestiones es parte de las tareas que realiza el cocinero, con autonomía de Ixs directivxs. Según me explicó el propio cocinero, él organiza las porciones considerando la cantidad de cupos para el comedor aprobados por el Consejo Escolar con los que cuenta la institución, Ixs chicxs que asisten y la mercadería que recibe. Más allá del número de niñxs que pueden comer en relación con el cupo aprobado por el Consejo Escolar, la cantidad de niñxs que comen efectivamente en el comedor es variable, y se encuentra condicionada por el menú establecido para el día. Por ejemplo, cuando se preparan milanesas ${ }^{6}$ es muy probable que asista

5 Me refiero a la Resolución de la Provincia de Buenos Aires N. 2066/15, "Procedimiento para la designación, funciones y tareas de los trabajadores auxiliares de la educación, para la limpieza institucional y el servicio alimentario escolar".

6 La milanesa es un plato muy popular de la cocina argentina. Consiste en un filete fino, normalmente de carne vacuna, pasado por huevo batido y luego por pan rallado, que se cocina frito o al horno. En la escuela, muchas veces, las milanesas se hacían con carne picada, pasada por huevo y luego por pan rallado. Si bien esta versión no es la popularmente conocida como milanesa, es una variante que solía elaborarse allí ante la falta de filetes o bifes de carne. 
la mayoría de Ixs chicxs inscritos en el comedor. El número de comensales también puede variar si asisten hermanxs menores de Ixs alumnxs; aunque esto es un problema señalado por el propio cocinero, al ser él el responsable de repartir las porciones es, en última instancia, quien define si comen o no. También es el cocinero quien establece si pueden o no repetir porción: aunque existe una norma no escrita que regula que en esta escuela "no se repite", el cocinero suele dar un plato más a algunxs niñxs (particularmente a aquellxs que asisten diariamente o tienen un mayor vínculo con él). Dado que el comedor funciona en un horario delimitado, es el cocinero quien les llama la atención con firmeza si llegan tarde. El propio cocinero me explicó que si no respetaban el horario de ingreso al comedor, Ixs niñxs que asisten al turno tarde (quienes almuerzan antes de ingresar a clases) terminan yéndose cuando toca el timbre sin haber terminado de almorzar, dejando la comida en el plato. Además, en el interior del comedor el cocinero y lxs auxiliares que colaboran con servir los platos son quienes establecen las pautas de comportamiento al pedir silencio, que coman en sus lugares, que no corran, no griten, que no se molesten mientras comen, y son ellxs quienes los retan cuando algunas de estas pautas son infringidas. Este protagonismo de Ixs auxiliares configura a la cocina y al comedor como lugares en los que ellxs toman las decisiones, incluso a veces limitando el poder del director de la escuela y de Ixs docentes. Esta situación producía buena parte de las tensiones alrededor del comedor.

Si bien el trabajo con Ixs niñxs me permitió resaltar la relevancia de este grupo de trabajadores, no había sido habitual que Ixs niñxs criticaran abiertamente lo que sucedía en el comedor, ni la comida que allí se cocinaba. Por este motivo lo que Antonia había dicho llamó mi atención. En primer lugar, por el modo en que la niña expresó su visión, vinculando las prácticas alimentarias a sentimientos de amor, o a su ausencia, me resultó muy relevante, en tanto incorporaba demandas que algunas personas enunciaban, pero que, al hacerlo de formas confrontativas, disminuían la sensibilidad a dichas expresiones. En ese sentido, las prácticas de comensalidad y la dimensión sensible mediante la que se promueven, aprenden o recrean eran puestas en el centro de la escena. En segundo lugar, llamó mi atención porque lo que Antonia decía se identificaba mucho más con la postura que mantenían docentes y miembrxs del EOE, que no tenían resquemores en decir que la comida era "mala", "desastrosa" o una "porquería". Esto me permitió poner en paridad los puntos problemáticos que señalaban algunxs niñxs con los de otrxs actores de la escuela, y entender que todas las perspectivas en juego eran parte de las tensiones políticas, aunque algunas de ellas no eran expresamente confrontativas. 
Advertir ese potencial me permitió resituar las otras actitudes de Ixs niñxs, aparentemente más pasivas, como parte de sus formas de participación en esas disputas suscitadas en torno al comedor. Mayoritariamente cuando eran retados por el cocinero al llegar tarde o jugar durante el almuerzo, solían aceptar los llamados de atención en silencio. Algunas veces criticaban que la comida estaba "picuda"7 o la milanesa dura, mientras tironeaban con los dientes, dichos o acciones que no exponían demasiado, pero que compartían entre pares e incluso conmigo. Cuando pretendían repetir se acercaban en silencio al cocinero con el plato en la mano, esperando la respuesta positiva o negativa de su parte. Estas formas menos confrontativas son, justamente, las que a esos niñxs le permiten negociar ingresar con hermanitxs menores, pedir doble ración de postre o repetir el plato de comida, pues en ese tipo de actitudes queda reconocido el lugar de autoridad que Ixs auxiliares detentan en el comedor. En algún sentido, la defensa de Lina de la comida de la escuela podría incluirse como parte de estos modos de intervenir.

Por otro lado, la visión de Antonia sobre mí como inspectora, que iba a "controlar", no es menor. Esta idea expuso al comedor como un espacio a ser vigilado. Se suma el considerar que por la presencia de la "inspectora" la comida era "mejor". Desconozco si Antonia había participado de otras instancias en las que se hacían presentes inspectores, pero sin duda entendía muy bien el sentido de la presencia de ellxs y el impacto que podía tener.

Tanto los dichos de Antonia como los de Lina me posibilitaron entender que Ixs niñxs también participaban de los conflictos que producía el comedor, no solo por exponer su malestar, como lo hizo Antonia, sino también por defender lo que allí se hacía, o al mantener una actitud aparentemente pasiva cada vez que reconocían el lugar de autoridad de Ixs auxiliares y el cocinero, pudiendo negociar con ellos algunos beneficios.

A continuación, recuperaré una serie de situaciones compartidas con alumnxs de sexto grado, con quienes realizamos la encuesta sobre alimentación escolar. Si bien son anteriores a los intercambios con Lina y Antonia, pudieron ser resituadas como políticas una vez que compartí ese momento en el comedor con las niñas.

\section{"Los que no comen en el comedor es porque no les gusta la comida"}

Una de las actividades que llevó más tiempo y situaciones compartidas con Ixs chicxs fue la elaboración de una encuesta sobre alimentación

7 Expresión utilizada por un niño para señalar que la comida era picante. 
escolar, que realizamos con el grupo de sexto grado del turno de la mañana. Los encuentros se realizaron en el aula, durante el horario de clases, generalmente con uno de sus docentes. La idea de hacer una encuesta surgió del director. Según él, la actividad nos permitiría conocer sobre la alimentación en la escuela y, a la vez, proveer contenidos para trabajar en matemáticas, pues luego Ixs chicxs realizarían el análisis de los datos con porcentajes y traslado a gráficos de los resultados. Para mí significaba una buena oportunidad para compartir con Ixs chicxs y conversar con ellxs sobre el tema.

En el cuarto encuentro con el grupo de sexto grado nos dedicamos a debatir sobre las preguntas que realizaríamos en la encuesta. Dado que el comedor resultaba un tema "sensible", tal como habían expresado el docente, Ixs miembrxs del EOE y el propio director, sugerían ciertas precauciones. El maestro expresó directamente que era mejor no incluir preguntas sobre el comedor, porque no todxs Ixs chicxs comían allí y, además, podía "herir susceptibilidades", expresión con la que se refería al modo en que el cocinero y Ixs auxiliares podían tomar la encuesta, su intención y resultados. Yo le propuse que lo evaluáramos con Ixs chicxs, y así fue. Mientras debatíamos sobre los temas y espacios a incluir en la encuesta, yo pregunté al grupo si les parecía que consideráramos preguntas sobre el comedor, Julián, uno de Ixs chicxs que más participaba en los encuentros, rápidamente respondió y se produjo el siguiente diálogo:

Julián: —Sí, preguntemos del comedor iYo voy al comedor!

Docente (quien intervino rápidamente): —Pero vos no vas sieeeempre al comedooorrrrr!!!!!! (Miró a Julián frunciendo el ceño.)

Julián (riéndose respondió, también rápidamente): —No, ivoy cuando me gusta la comida que hay!

Docente: —Ah, iqué vivo!

[Al advertir la tensión me dirigí a Julián para que se explayara.]

Silvina: —iAhhhhh! Está bien... ¿Y cuáles son las que te gustan?

Julián: - Milanesas...

Docente (interrumpiéndolo): —Pastel de papa....

Julián (riéndose, como un gritito): —Sí, sí, también. 
Silvina: —Y, Julián, ¿para vos comen muchos chicos en el comedor?

Julián: - A veces, a veces sí, como cuando hay milanesas, ahí se quedan muchos.

Silvina: —¿Y cuándo no se quedan?

Julián: —Cuando hay guiso, guiso de arroz. Yo me quedo, a mí me gusta el guiso de arroz.

Minutos después, mientras considerábamos opciones de respuestas a la pregunta "¿Qué postre te gusta más del comedor?" se volvió a producir un debate entre Julián y su docente. Julián fue quien propuso esa pregunta, y luego entre varixs chicxs fueron diciendo opciones: ialfajor!, ibanana!, igalletitas con dulce! Iban gritando cada una de las propuestas de opciones para la encuesta. Cuando uno de Ixs chicxs propuso que agregáramos como opción "mandarina", el maestro volvió a intervenir, y se produjo la siguiente interacción:

Docente: - Mandarina mucho no, ieh! Nunca les dan mandarina...

Silvina: —¿Por?

Docente: - Y... Porque después los porteros se enojan porque ensucian la escuela con las cáscaras. iDejan tiradas las cáscaras por toda la escuela!

Silvina: - Ahhhh... Pero, entonces, ¿pongo o no pongo mandarina? ¿Qué dicen? (Dirigiéndome a Ixs chicxs.)

Julián (interviniendo rápidamente): —Sí, sí, poné, porque a veces dan mandarina. (Mientras me respondía miró fijo al docente, como tratando de convencerlo.)

Docente: - Mmmmmm. (Mueve la cabeza hacia los costados produciendo un gesto que interpreto como de duda.)

Julián: —Sí, a veces...

En algunos encuentros más logramos terminar la encuesta y semanas después pudimos coordinar para que la aplicáramos a Ixs cuatrocientxs alumnxs de la escuela. Incluimos en el cuestionario varias preguntas sobre el comedor (figura 1): 
Figura 1

Encuesta sobre alimentación escolar elaborada con Ixs chicxs de sexto grado,

turno de la mañana (octubre de 2015)

\section{Encuesta sobre alimentación escolar}

Lee atentamente las preguntas y sus opciones antes de seleccionar las respuestas Marcá tus respuestas elegidas con una $\mathrm{X}$ en el recuadro

Sexo: $\mathbf{F} \square \mathbf{M}$

Edad: ............

Grado:

1) ¿Comes en el comedor de la escuela?

- Sí

- No

(Si respondes que NO, debes pasar a la pregunta 5)

2) Si comes en el comedor de la escuela, ¿con qué frecuencia lo hiciste en la última semana?

- 1 o 2 veces

- 3 o 4 veces

- Todos los días

3) En caso de comer en el comedor, ¿qué comida te gusta más? (Podés seleccionar hasta 3 opciones) - Tarta con ensalada

- Pastel de papas

- Guiso

- Milanesas con puré

- Albóndigas con arroz

- Otros:

4) ¿Qué postre te gusta más del comedor?

- Mandarinas

- Alfajor

- Manzana

- Banana

- Galletita con dulce

- Gelatina

- Otros:

5) ¿Traes algo para comer en la escuela?

- Siempre

- A veces

- Nunca

(Si respondes NUNCA, debes pasar a la pregunta 7)

6) Si traes algo para comer, ¿qué traes? (Podés elegir hasta 2 opciones)

- Golosinas

- Cereales

- Papas fritas, chizitos, etc.

- Galletitas

- Frutas

- Otros:

7) ¿Traes algo para tomar en la escuela?

- Siempre

- A veces

- Nunca

(Si respondes NUNCA, debes pasar a la pregunta 9) 
8) Si traes algo para tomar, ¿qué traes?

- Jugos

- Gaseosas

- Agua

- Otros:

9) ¿Traes dinero para comprar algo para comer o tomar en el kiosco de la escuela?

- sí

- NO

(Si respondes que NO, debes pasar a la pregunta 13)

10) Si traes dinero a la escuela, ¿cuántas veces trajiste dinero en la última semana?

- 1 o 2 veces

- 3 o 4 veces

- Todos los días

11) Cuando traes dinero, ¿cuánto traes en general?

- Hasta 5 pesos

- De 5 a 10 pesos

- Más de 10 pesos

12) ¿Qué es lo que más compras en el kiosco? (Podés elegir hasta 6 opciones)

- Gaseosas

- Alfajores

- Papas fritas, chizitos, palitos

- Caramelos, chupetines o chicles

- Girasoles

- Chocolates

- Turrones

- Té o café

- Tutucas

- Empanadas

- Panchos

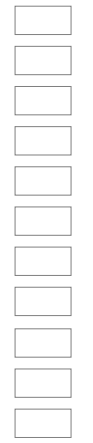

13) ¿Tomas el desayuno que preparan en la escuela?

- sí

- NO

(Si respondes que NO, has finalizado la encuesta iMuchas gracias!)

14) Si tomas el desayuno que preparan en la escuela, ¿cuántas veces tomaste el desayuno en esta semana? - 1 o 2 veces

- 3 o 4 veces

- Todos los días

15) ¿Qué te gusta comer del desayuno que preparan en la escuela? (Podés elegir hasta 3 opciones)

- Facturas

- Alfajores

- Pan con queso

- Pan con jamón

- Galletas de grasa

- Pan solo

- Galletitas dulces

- Obleas

¿Qué te gusta tomar en el desayuno que preparan en la escuela?

- Matecocido

- Leche

- Jugo

- Leche con chocolate

Fuente: elaboración propia 
Finalmente, el docente y lxs niñxs no trabajaron los datos en matemáticas por falta de tiempo, por lo que yo me ocupé de sistematizar algunos resultados para que pudiéramos discutir con algunxs de ellxs y así poder dar un cierre al trabajo compartido. Hice una presentación en Power Point con algunas fotos del día que habían aplicado la encuesta y los resultados estimativos en gráficos. El primer dato que les mostré se refería a que el $58 \%$ de Ixs chicxs encuestadxs asistían al comedor, y luego vimos que más de $50 \%$ de Ixs chicxs que van al comedor lo hacen una a dos veces por semana. Cuando les pregunté qué pensaban sobre eso, Julián respondió:

Julián: —No vienen porque no les gusta la comida... Los que no comen en el comedor es porque no les gusta la comida, o tal vez comen en la casa. O son delicados con la comida.

Silvina: - ¿Delicados?

Julián: -Sí, exigentes.

En esta situación Julián y Belén, otra alumna de sexto que también participó en este intercambio en un sentido muy similar al del Julián, expusieron el gusto como elemento central para tomar decisiones en torno a lo que eligen comer o no comer en la escuela. Cabe aclarar que asistir al comedor no es obligatorio, sino que allí van Ixs niñxs que "lo necesitan". La escuela, en función de la cantidad de alumnxs y la demanda de ellxs para asistir al comedor, cuenta con una determinada cantidad de cupos, por los que el Gobierno provincial asigna un monto de dinero por niñx, por día, destinado al almuerzo. En ese sentido puede comprenderse que para el docente "no venir siempre" podía ser un aspecto criticable, en cuanto aquellxs que asisten solo cuando les gusta la comida podrían no necesitar verdaderamente comer allí. Por su parte, Julián defendía la postura de venir cuando la comida le gustaba o la posibilidad de ser "delicados" o "exigentes" con lo que comían, sin que ello presentara contradicción.

En un estudio sobre comedores escolares en la provincia de Córdoba, Ibañez \& Huergo (2012) advirtieron que entre Ixs camarerxs ${ }^{8}$ de los comedores escolares existe una visión negativa sobre la selectividad que aplican Ixs niñxs en relación con los alimentos, la cual se expresa en la fórmula "Encima que les das, eligen". Para estas autoras, esa valoración sobre Ixs niñxs es parte de una operatoria sobre los cuerpos que performa silenciosamente

8 En la provincia de Córdoba, a diferencia de la provincia de Buenos Aires, el sistema de comedores escolares se organiza mediante la terciarización del servicio de preparación de alimentos. Las comidas llegan en viandas y en la escuela son repartidas por Ixs camarerxs. 
formas de sensibilidad, modos de ser y estar con otros, y que por ende oculta tras la "asistencia" una política de identidad que condiciona las posibilidades de ser y desear de Ixs niñxs. Sin embargo, aquí lo que resulta significativo es lo que pone en tensión esta exposición del gusto como elemento central para elegir comer, o no, en la escuela.

Si bien en algunas instituciones escolares hay cronogramas fijos de comidas, es decir que lxs niñxs saben qué van a cocinar cada uno de los días de la semana, en esta escuela en particular el menú varía de acuerdo a los recursos de los que se dispone cada día, estableciendo un cronograma más flexible. Sin embargo, como la cocina se encuentra en un lugar central del edificio escolar, Ixs niñxs rápidamente pueden saber cuál será el menú de cada día. Desde la puerta se puede observar al cocinero preparando los alimentos y, más tarde, los platos servidos sobre las mesas; así como también se puede sentir desde cualquier punto de la escuela el olor de las preparaciones. Por ello, Ixs niñxs pueden anticipar, antes de entrar al comedor, cuál será el menú, y algunxs de ellxs eligen quedarse a almorzar o no. Más allá de las valoraciones sobre las definiciones de Ixs niñxs, son ellxs quienes en muchas oportunidades - deciden si comen o no, si terminan el plato o no, si piden repetir ración o no.

David Le Breton, en su obra El sabor del mundo (2009), aborda específicamente la formación del gusto, atendiendo a las experiencias infantiles. Tal como expone el autor,

aprender a saborear un plato consiste ante todo en ingresar a un registro cultural cuyos valores se comparten. El gusto alimentario es un dato social y cultural, una forma interiorizada de predilección y de rechazo [...]; se evidencia mediante percepciones gustativas y apetencias singulares frente a los sabores, a los alimentos, a las bebidas, induciendo no solo una nutrición, sino también valores y sentimientos, es decir, el placer y el disgusto, las predilecciones y los rechazos (p. 274).

Le Breton señala la incidencia de, por ejemplo, las experiencias escolares en las que el grupo de pares colabora con la ampliación de las preferencias y las propuestas alimentarias del grupo familiar. En este sentido, que algunxs niñxs de la escuela coloquen el gusto sobre la mesa para pensar justamente la alimentación en contexto escolar resulta de una relevancia singular. Sobre todo, porque, tal como fui reconstruyendo, el modo en el que muchas personas presentaban el problema del comedor tenía que ver más con tensiones y disputas por las posiciones en la escuela de directivxs, docentes y auxiliares que con los aspectos alimentarios en sí. Sin duda ello afecta y define el modo en el que se les da de comer a Ixs niñxs en la escuela, pero las discusiones centrales pasan más por conflictos 
que trascienden las prácticas en torno a la alimentación. Y si se pone el foco en los aspectos directamente vinculados con la elaboración de la comida, la perspectiva de Ixs niñxs no suele ser considerada como parte de las voces autorizadas para elaborar y pensar el problema. En aquellos casos en los que se piensan momentos para trabajar con Ixs niñxs, priman las posiciones que tradicionalmente estructuran la escuela, como la de docente-alumnx. En una oportunidad, y como parte del proyecto sobre alimentación en la escuela, dos pediatras del hospital más cercano asistieron a la escuela para brindar un taller sobre "alimentación saludable". La actividad central entusiasmó a Ixs niñxs: debían elaborar la cartelería de un buffet escolar o restaurante "saludable", consignando el nombre del lugar y varias opciones de menú. En grupo, y con ayuda de una docente, Ixs niñxs elaboraron los afiches y los presentaron. Si bien la actividad fue muy amena y contó con el entusiasmo de todxs, el taller no logró abrir a debate aspectos que problematizaran las prácticas alimentarias escolares. Lxs niñxs ponían opciones de menú previendo que consignar gaseosas, por ejemplo, estaba "mal", como si se tratara de una tarea escolar que puede ser evaluada positiva o negativamente. Por ello, en este contexto, la forma en la que estos niñxs lograron exponer la centralidad del gusto como parte de sus elecciones y criterios para asistir al comedor reviste importancia política, en cuanto posibilita resituar los modos habituales en los que se define el tema de la alimentación escolar.

Otra de las situaciones en las que se evidencia el predominio de la lógica escolar por sobre un abordaje del problema de la alimentación en el contexto escolar es la situación en torno a las mandarinas. Si bien muchxs niñxs señalaron que les gustaba comer mandarinas, no se les daba como postre porque las cáscaras de esta fruta producían mucho desorden, lo cual significaba más trabajo para Ixs auxiliares encargados de la limpieza del edificio escolar. La decisión que se tomó frente a este problema de la suciedad de las cáscaras de mandarina fue dejar de dar esa fruta. En otra situación también puede evidenciarse la prevalencia de criterios definidos en torno a elementos distantes del gusto de Ixs niñxs: como parte del trabajo de elaboración de la encuesta junto con Ixs alumnxs pensamos en repartir manzanas, pero el director nos explicó que, en general, Ixs chicxs no consumían esta fruta y terminaba por pudrirse en los cajones. A cambio nos ofreció repartir turrones de maní, porque si pasaba algo (no se repartían todos, se suspendía la elaboración de la encuesta, etcétera), no se echarían a perder. Es decir que, bajo diferentes argumentos, dar fruta en la escuela terminaba por restringirse, repartiéndose en su lugar alfajores o turrones por practicidad, aunque se trate de alimentos que, por su alto contenido en azúcar refinada, no pueden considerarse como los más "saludables". 


\section{Comentarios finales}

En este trabajo sintetizo algunos análisis en torno a la perspectiva de Ixs niñxs sobre el comedor escolar y las prácticas de comensalidad en la escuela. Por insertarse dentro de un entramado de tensiones sobre el tema, la perspectiva de Ixs niñxs, como las de otrxs actores, son aquí consideradas como políticas. Como he mostrado, mediante formas más o menos difusas, Ixs niñxs entran en la disputa sobre el problema de la alimentación en el contexto escolar, y lo hacen poniendo en el foco elementos centrales del tema. En primer lugar, la mirada de Ixs niñxs permitió que el cocinero y Ixs auxiliares fueran considerados cabalmente como parte del problema, cuando suelen ser — tanto desde los discursos escolares y las investigaciones de salud y educación - poco o nulamente considerados. En la vida cotidiana de la escuela el cocinero y Ixs auxiliares de servicio son actores centrales para el funcionamiento del comedor, y han logrado configurar su trabajo y espacio de trabajo como un locus desde el cual disputan su lugar en la escuela. Mediante el dar de comer, acompañar y cuidar a Ixs niñxs durante el momento del comedor, desarrollan una tarea muy importante, por la que intervienen en la socialización escolar de lxs niñxs, siendo justamente uno de los elementos que genera tensiones con otrxs actores, como directivxs y docentes. En segundo lugar, Antonia, al valorar la comida por su "onda" o "amor" al ser elaborada, introdujo elementos novedosos para pensar las prácticas de comensalidad. Hasta entonces nadie los había expuesto como estructurantes para analizar la calidad de la comida. Para esta niña, los alimentos elaborados en la escuela deben ser hechos incorporando estos ingredientes, lo que puede posibilitar que la comida sea buena o no. En tercer lugar, Julián logró exponer otro elemento que para muchxs niñxs era clave para asistir o no al comedor: el gusto. Lejos de encerrarse en aquellas valoraciones morales que indican que cuando se necesita comer en los espacios de comensalía públicos no se puede elegir, Julián sostuvo en diferentes situaciones que el hecho de que les guste la comida es prioritario.

De este modo, la visión de Ixs niñxs aporta elementos sustanciales para replantear el tema de la alimentación en un contexto escolar, en general, y del comedor escolar, en particular. Colocando en el centro nodos de las prácticas alimentarias, Ixs niñxs me permitieron analizar que la alimentación en la escuela se rige por lógicas escolares que terminan por priorizar disputas por posiciones o aspectos organizativos, que se alejan de hacer un planteamiento real sobre la calidad de la alimentación de lxs niñxs.

Considerar la potencialidad política de las perspectivas de Ixs niñxs no solo resulta central para poder realizar planteamientos originales sobre el tema de la alimentación, sino profundamente necesaria. Para quienes 
hemos pasado la mayor parte de nuestras vidas transitando el espacio escolar, es un hecho la naturalización de las formas y exigencias que organizan a las escuelas. En este caso, la participación de Ixs niñxs me permitió no solo extrañarme de dichas lógicas, sino también incorporar elementos novedosos para pensar el problema, los cuales suelen ser omitidos por el campo de los estudios sobre la alimentación en la escuela, así como por los propios actores escolares.

Por último, me interesa señalar que las visiones de Ixs niñxs aquí reconstruidas y su posibilidad de contemplarlas revisten importancia política en relación con el actual sistema alimentario. La industria de los alimentos procesados ha distanciado a las personas de los modos de acceder a las fuentes de esos alimentos, lo que ha producido una suerte de enajenación con respecto a la procedencia y el modo de elaboración de la comida. Le Breton (2009) retoma a Bachelard, quien planteó que "apartar al niño de la cocina es condenarlo a un exilio que lo aleja de sueños que nunca conocerá. Los valores oníricos de los alimentos se activan al realizar su preparación" (pp. 274-275). La cercanía con la elaboración de los alimentos inicia a Ixs niñxs en el discernimiento de los sabores y su importancia. Sin la posibilidad de elegir sabores, rechazarlos, conocer y reconocer los alimentos, no hay formas posibles de construir procesos alimentarios conscientes.

Sin duda, en este trabajo he dejado por fuera muchas otras posibles lecturas que habilitan las perspectivas de Ixs niñxs, como, por ejemplo, la producción de sensibilidades que se promueve desde el espacio escolar. Tampoco ha sido considerado el modo en el que se expresan muchos de los malestares y las tensiones alrededor de la alimentación en la escuela, cuyas manifestaciones remiten, también, a aspectos sensibles de la vida social. Estas líneas de profundo interés para el estudio en el que se enmarca este trabajo serán tenidas en cuenta en análisis futuros. Pero ya partiendo de algunas certezas, como la relevancia de la mirada de lxs niñxs para el estudio de los procesos alimentarios, en general, y, en particular, en el espacio escolar; la paridad de sus visiones en relación con la de otrxs actores sociales, y la consideración de su agencia y participación política en la vida cotidiana.

\section{Agradecimientos y aclaraciones}

Una primera versión de este trabajo fue presentada en las VIII Jornadas sobre Etnografía y Procesos Educativos en Argentina. Agradezco a Ixs participantes de este espacio por sus comentarios y sugerencias para hacer crecer este trabajo. Asimismo agradezco a mis directoras de tesis, las doctoras Diana Milstein y Analía Meo, y a mis compañerxs del Grupo de Estudio y Trabajo Antropología y Educación, del CAS-IDES, por sus aportes a este escrito. 


\section{Sobre la autora}

Silvina del Carmen Fernández es profesora en Ciencias de la Educación y actualmente doctoranda del Programa de Posgrado de Ciencias Sociales de la Universidad Nacional de General Sarmiento-IDES, Argentina. Integra el Grupo de Estudio y Trabajo Antropología y Educación, del Centro de Antropología Social (IDES), y es miembro del Grupo Argentina de la Red Internacional de Etnografía con Niñas, Niños y Adolescentes (RIENN). Se desempeña como docente en el Instituto de Formación Docente Continua de la ciudad de Bariloche, Argentina.

\section{Referencias}

Abélès, M. (2004). La antropología política: nuevos objetivos, nuevos objetos. En El ayer y el hoy: lecturas de antropología política, vol. 1, Hacia el futuro. Madrid: Universidad Nacional de Educación a Distancia.

Batallán, G. (2003). El poder y la autoridad en la escuela. La conflictividad de las relaciones escolares desde la perspectiva de los docentes de infancia. Revista Mexicana de Investigación Educativa, 8(19), 679-704. Recuperado de https://www.redalyc.org/pdf/140/14001906.pdf

Batallán, G. \& Campanini, S. (2008). La participación política de niñ@s y jóvenesadolescentes. Contribución al debate de democratización de la escuela. Cuadernos de Antropología Social, 28, 85-106. Recuperado de https:// www.redalyc.org/pdf/1809/180913915005.pdf

Bonzi, N. \& Bravo-Luna, M. (2008). Patrones de alimentación en escolares: calidad versus cantidad. Revista Médica Rosario, 74(2), 48-57. Recuperado de https://pdfs.semanticscholar.org/5d0d/ce59d10f72cd1fd85ada 7d057e095dcc4ae7.pdf?_ga=2.254488200.1207902191.15949338961604681762.1594933896

Bray, T. L. (2003). The commensal politics of early States and empires. En T. L. Bray (Ed.), The Archaeology and Politics of Food and Feasting States and Empires (pp. 1-13). New York: Plenum.

Cervera-Montejano, M. D. (2009). "¿Quién me cuida?": características de las interacciones entre los niños mayas yucatecos y sus cuidadores. Estudios de Antropología Biológica, XIV(X), 547-565. Recuperado de https://www. researchgate.net/publication/254258936_Quien_me_cuida_Caracteristicas de_las_interacciones_entre_los_ninos_mayas_yucatecos_y_sus_cuidadores

Clarke, M. J. (2001). Akna feasting: An ethnoarchaeological perspective. En M. Dietler \& B. Hayden (Eds.), Feasts. Archaeological and Ethnographic Perspectives on Food, Politics, and Power (pp. 144-167). Washington, D. C.: Smithsonian Institution Press.

Cole, M. \& Cole, S. (1996). The Development of Children. New York: Freeman.

Dietler, M. (1996). Feast and commensal politics in the political economic: Food, power and status in prehistory Europe. En P. Wiessener \& W. Schiefenhövel (Eds.), Food and the Status Quest (pp. 87-125). Oxford: Berghahn.

Dietler, M. (2001). Theorizing the feast: Ritual of consumption, commensal politics, and power in African contexts. En M. Dietler \& B. Hayden (Eds.), Feasts. 
Archaeological and Ethnographic Perspectives on Food, Politics, and Power (pp. 65-114). Washington, D. C.: Smithsonian Institution Press.

Foucault, M. ([1976] 2003). Historia de la sexualidad. Vol. I, La voluntad del saber. Buenos Aires: Siglo XXI.

Ibañez, I. \& Huergo, J. (2012). "Encima que les dan, eligen", políticas alimentarias, cuerpos y emociones de niños/as de sectores populares. Revista Latinoamericana de Estudios sobre Cuerpos, Emociones y Sociedad, 4(8). Recuperado de https://www.redalyc.org/pdf/2732/273224053004.pdf

Le Breton, D. (2009). El sabor del mundo. Una antropología de los sentidos. Buenos Aires: Nueva Visión.

LeVine, R. A. (1999). An Agenda for Psycological Anthropology. Ethos, 27(1), $15-24$.

Mead, G. H. (1934). Mind, Self, and Society. Chicago: University of Chicago Press.

Mignot, J. M. (1996). Exemples de techniques d'acquisition de produits alimentaires mises en œuvre par les enfants Massa Bugudum. En I. de Garine, A. Froment, Ch. Binam-Bikoi \& J.-F. Loung (Eds.), Bien manger et bien vivre. Anthropologie alimentaire et dévéloppement in Afrique intertropicale: Du biologique au social (pp. 425-432). París: L’Harmattan.

Milstein, D., Fernández, M. I., García, M. A., García, S. M. \& Paladino, M. (2006). Panorama de la antropología y la educación escolar en la Argentina: 19822006. Anuario de Estudios en Antropología Social, 77-94.

Milstein, D. \& Otaso, A. (2013). Participación política de niños y niñas en la cotidianeidad de las escuelas. Revista Argentina de Estudios de Juventud, 7. Recuperado de https://perio.unlp.edu.ar/ojs/index.php/revistadejuventud/ article/view/2039

Ochs, E. \& Shohet, M. (2014). La estructuración cultural de la socialización durante las comidas. En L. R. Piaggio \& A. M. Solans (Comps.), Enfoques socioculturales de la alimentación (pp. 259-276). Buenos Aires: Akadia.

Padilla, I. S. (2011). Prevalencia de sobrepeso-obesidad y factores asociados con valor predictivo-preventivo en escolares de 6 a 11 años de Río Gallegos, Santa Cruz, Argentina. Salud Colectiva, 7(3), 377-388. Recuperado de https://doi.org/10.18294/sc.2011.272

Remorini, C. (2015). El papel de los niños en la obtención, elaboración, circulación y consumo de alimentos en comunidades Mbya (Argentina). Anthropology of Food, 9. Recuperado de https://doi.org/10.4000/aof.7770

Rogoff, B., Moore, L., Behnosh, N., Dexter, A., Correa-Chavez, M. \& Solís, J. (2007). Children's development of cultural repertoires through participation in everyday routines and practices. En J. E. Grusec \& P. D. Hastings (Eds.), Handbook of Socialization: Theory and Research (pp. 490-515). Nueva York: The Guilford Press.

Rogoff, B., Paradise, R., Mejía-Arauz, R., Correa-Chávez, M. \& Angelillo, C. (2003). Firsthand learning through intent participation. Annual Review of Psychology, 54(1), 175-203. Recuperado de https://www.annualreviews. org/doi/abs/10.1146/annurev.psych.54.101601.145118

Swartz, M., Turner, V. \& Tuden, A. (1966). Introduction. En Political Anthropology. Chicago: Aladine. 
Torres, A. A. (2013). Gordos e "gordisses": estudo etnográfico de pacientes obesos no Hospital Universitário de Brasilia (tesis de maestría). Universidad de Brasilia, Brasilia, Brasil. Recuperado de https://repositorio.unb.br/handle/ 10482/13904

Tovo, M. (2013). Valoración del estado nutricional y descripción de hábitos relacionados con el riesgo de desarrollar sobrepeso y obesidad en adolescentes: comparación entre dos escuelas de gestión pública y privada en la localidad de Tortuguitas, provincia de Buenos Aires (tesis de licenciatura). Universidad de Belgrano, Buenos Aires, Argentina. Recuperado de http://repositorio. ub.edu.ar/handle/123456789/1326

Wiessener, P. (2001). Feasting and value: Enga feasts in historical perspective (Papua New Guinea). En M. Dietler \& B. Hayden (Eds.), Feasts. Archaeological and Ethnographic Perspectives on Food, Politics, and Power (pp. 115-143). 